\title{
PHASE TRANSITION FOR AGS UPGRADE
}

\section{BOOSTER TECHNICAL NOTE}

NO. 200

M. Meth

SEPTEMBER 17, 1991

ALTERNATING GRADIENT SYNCHROTRON DEPARTMENT BROOKHAVEN NATIONAL LABORATORY

UPTON, NEW YORK 11973 


\title{
PHASE TRANSITION FOR AGS UPGRADE
}

\author{
M. Meth
}

\section{Introduction}

Phase transition for the AGS RF Upgrade can require the power amplifiers to handle very large reactive currents, resulting in the power output tube being driven into the positive-grid region (class $\mathrm{AB}_{2}$ operation) or even current limited. Normally, the cavity is non-resonant. The reactive component of beam current resonates with the cavity and provides a tuned or resonant load for the power amplifier. At phase transition the reactive component of beam current changes abruptly from lead to lag; from an equivalent capacitance to an equivalent inductance. The power output tube must provide a current that in addition to a fixed real component (beam power, ferrite loss) has a reactive component, which is equal to the full change of beam current. Normally the reactive component of beam current is larger than its real component.

By operating the cavity at resonance just prior to phase transition the tube current before and the tube current after transition are (complex) conjugate. The absolute value of tube current is significantly less than would be required by utilizing the former scenario. The difference between the two scenarios is illustrated by the phase diagrams of Figure 1.
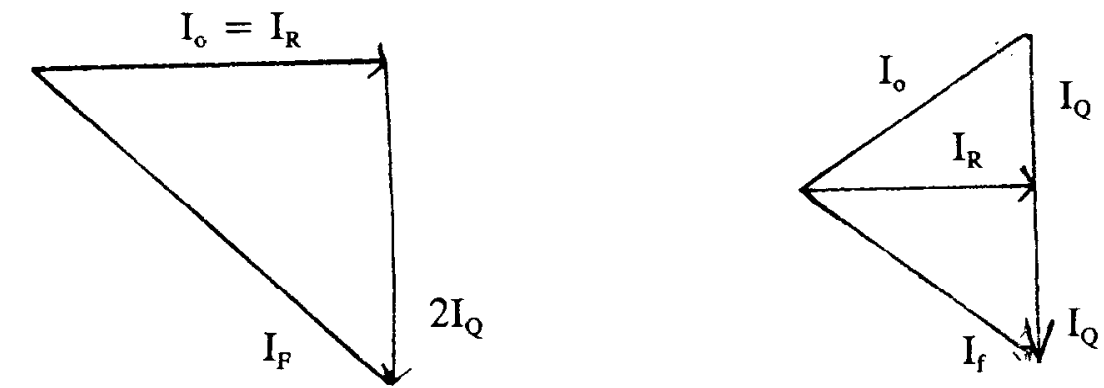

$$
I_{f}=2 I_{Q} \sqrt{1+\frac{I_{R} 2}{4 I_{Q} 2}}
$$

$$
I_{o}=I_{f}=I_{Q} \sqrt{1+\frac{I_{R} 2}{I_{Q} 2}}
$$

$$
1 \text { A - Resonant Load }
$$

1B - Resonant Cavity

Figure 1

Phasor Diagram of Cavity Current Before and After Phase Transition

$I_{R}=$ Real Component of Cavity Current

$\mathrm{I}_{\mathrm{O}}=$ Reactive Component of Beam Current

$\mathrm{I}_{\mathrm{O}}=$ Cavity Current Before Transition

$I_{f}=$ Cavity Current After Transition 


\section{PARAMETERS}

The parameters employed for this study are:

$$
\begin{aligned}
& \mathrm{N}=9 \times 10^{13} \text { protons per pulse } \\
& \quad \text { (includes a } 50 \% \text { safety factory) }
\end{aligned}
$$

The real and quadratune components of beam current are calculated as:

$$
\begin{aligned}
& \mathrm{I}_{\mathrm{R}}{ }^{1}=6.29 \mathrm{~A} \\
& \mathrm{I}_{\mathrm{Q}}=8.66 \mathrm{~A}
\end{aligned}
$$

The cavity current due to ferrite dissipation is calculated as:

$$
\mathrm{I}_{\mathrm{R}}{ }^{11}=3.25 \mathrm{~A}
$$

thus

$$
I_{R}=I_{R}{ }^{1}+I_{R}{ }^{11}=9.54 \mathrm{~A}
$$

The maximum cavity current for the two scenarios described are calculated as

for $\mathrm{A}$ (resonant load) $=19.77 \mathrm{~A}$

for $\mathrm{B}$ (resonant cavity) $=12.88 \mathrm{~A}$

Referred to the plate of the output tube, the fundamental component of current has a peak value of

$$
\begin{aligned}
& \text { for } A=79.1 \mathrm{~A} \\
& \text { for } \mathrm{B}=51.5 \mathrm{~A}
\end{aligned}
$$

For class B operation the peak value of plate current is approximately

$$
\begin{aligned}
& \text { for } A=190 A \\
& \text { for } B=120 A
\end{aligned}
$$

The load impedance phase angle after transition is calculated as

$$
\begin{aligned}
& \text { for } A=61.2^{\circ} \text {, lag } \\
& \text { for } B=42.2^{\circ} \text {, lag. }
\end{aligned}
$$

\section{SYSTEM DESCRIPTION}

It is proposed that the amplifier load be detuned prior to reaching transition energy. A pulse is applied to the phase-shifter within the cavity tuning loop. The pulse width is selected to approximate the loop settling time. The pulse amplitude is chosen to advance the phase (in 
the steady-date) by $42.2^{\circ}$, corresponding to the load impedance angle for maximum beam intensity. At transition energy the phase is retarded and terminates as a lag angle that is dependent on the beam intensity. The lag angle is less than $42.2^{\circ}$. Table I gives the lag angle after transition as a function of beam intensity. Following transition the tuning loop retunes the cavity, phase angle of $0^{\circ}$. Figure 2 gives the load impedance phase angle for a beam intensity of $9 \times 10^{13}$ and $5.4 \times 10^{13}$. For this figure it is assumed that the cavity tuning loop settling time is 1.5 milliseconds. Transition energy is at time $\gamma_{\mathrm{T}}$.

\begin{tabular}{|c|c|c|c|c|c|c|}
\hline \multirow{2}{*}{$\begin{array}{l}\mathrm{N} \\
\mathrm{x} 10^{13}\end{array}$} & \multicolumn{2}{|c|}{ BEAM CURRENT } & \multicolumn{2}{|c|}{ BEFORE TRANSITION } & \multicolumn{2}{|c|}{ AFTER TRANSITION } \\
\hline & $I_{1}$ (Amp) & $\mathrm{L}_{\mathrm{Q}}(\mathrm{Amp})$ & Lead Angle & $\begin{array}{c}\text { Tube Current } \\
\text { (Amp) }\end{array}$ & Lag Angle & $\begin{array}{c}\text { Tube Current } \\
\text { (Amp) }\end{array}$ \\
\hline 0 & 0 & 0 & $42.2^{\circ}$ & 17.5 & $-42.2^{\circ}$ & 17.5 \\
\hline 1.8 & 2.14 & 1.73 & $42.2^{\circ}$ & 24.4 & $-8^{\circ}$ & 18.3 \\
\hline 3.6 & 4.30 & 3.48 & $42.2^{\circ}$ & 31.2 & $16.8^{\circ}$ & 24.2 \\
\hline 5.4 & 6.45 & 5.22 & $42.4^{\circ}$ & 38 & $30^{\circ}$ & 32.5 \\
\hline 7.2 & 8.56 & 6.93 & $42.4^{\circ}$ & 44.7 & $37.5^{\circ}$ & 41.7 \\
\hline 9. & 10.7 & 8.66 & $42.2^{\circ}$ & 51.5 & $42.2^{\circ}$ & 51.5 \\
\hline
\end{tabular}

TABLE I

Tube Current, Amplitude and Phase, at Transitron

$\mathrm{I}_{1}=$ Beam Current

$\mathrm{I}_{\mathrm{Q}}=$ Reactive Component of Beam Current

All currents are given by peak value of fundamental.

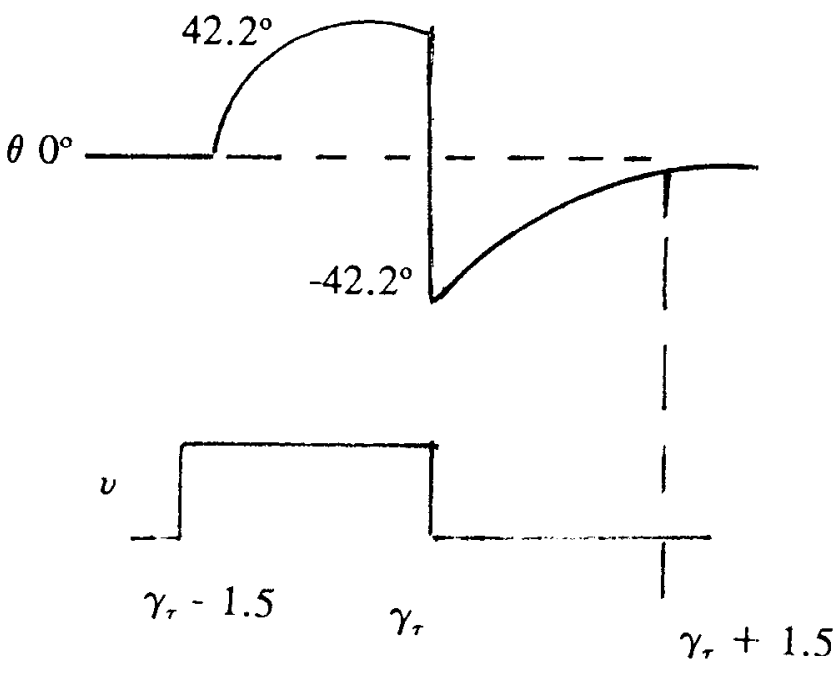

$N=9 \times 10^{13}$
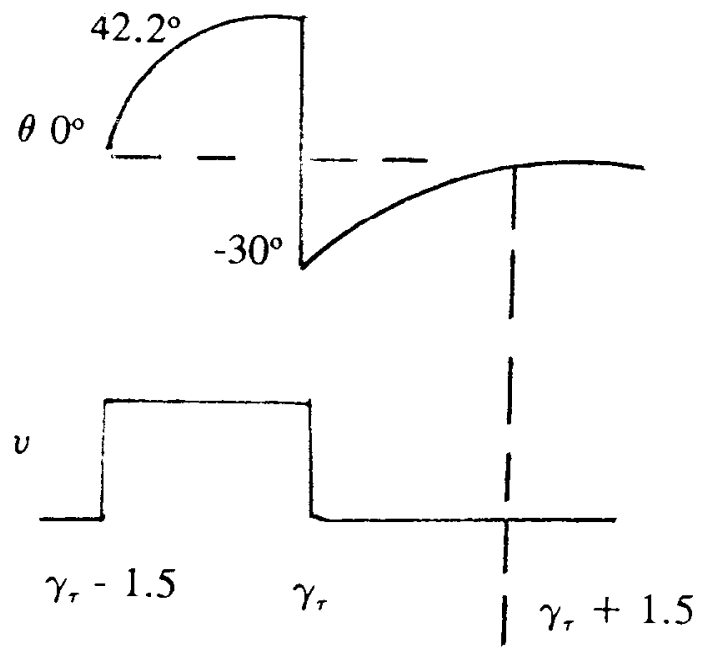

$\mathrm{N}=5.7 \times 10^{13}$

Figure 2 


\section{Output Stage}

The design of the power amplifier output stage is based on the current and power required at phase transition. Using the detuning scenario of Figure 1B and the Thomson-CSF 573 tetrode operating as a class $\mathrm{AB}_{1}$ amplifier the "load line" or locus of operation was developed. This development required a number of iterations correcting for the 3/2's power law of tube current and correcting for the phase shift between plate current and grid voltage. The locus is a rotated ellipse on the tube's constant-current characteristic and is given in Figure 3.

The tube is biased at:

$$
\begin{aligned}
& \mathrm{E}_{\mathrm{bb}}=12 \mathrm{Kv} \\
& \mathrm{E}_{\mathrm{c} 2}=1500 \text { volts } \\
& \mathrm{E}_{\mathrm{c} 1}=-380 \text { volts }
\end{aligned}
$$

resulting in a quiescent plate current of 5 amperes. The operating locus is given by the parametric equation

$$
\begin{aligned}
& e_{b}=12-10 \sin w t \quad K v \\
& e_{c}=-380+380 \sin \left(w t+35^{\circ}\right) \quad \text { volts. }
\end{aligned}
$$

The current waveform is given in Figure 4 and is compared to a sinusoid. Harmonic analysis of the current-waveform gives a fundamental component of

$$
\mathrm{i}_{\mathrm{b}}=53.7 \sin \left(\mathrm{wt}+42^{\circ}\right) \quad \text { Amperes. }
$$

and an average value of 32.7 Amperes. The load voltage is 10 sin wt in Kv. The load-impedance phase angle is $42^{\circ}$ lead and the load power is $200 \mathrm{KW}$.

The locus was analyzed and the electrode current and dissipation calculated. The results are given in Table II and compared with the tube ratings. Table II also contains an estimate of these parameters for maximum acceleration.

\begin{tabular}{||l|c|c|c||}
\hline & $\begin{array}{c}\text { Phase } \\
\text { Transition }\end{array}$ & $\begin{array}{c}\text { Maximum } \\
\text { Acceleration }\end{array}$ & $\begin{array}{c}\text { Tube } \\
\text { Limit }\end{array}$ \\
\hline Peak Plate Current & $125 \mathrm{~A}$ & $80 \mathrm{~A}$ & $400 \mathrm{~A}$ \\
\hline Average Plate Current & $32.7 \mathrm{~A}$ & $24 \mathrm{~A}$ & \\
\hline Plate Dissipation & $193 \mathrm{KW}$ & $93 \mathrm{KW}$ & $300 \mathrm{KW}$ \\
\hline Peak Screen Current & $3 \mathrm{~A}$ & 3 & \\
\hline Average Screen Current & $.45 \mathrm{~A}$ & $.7 \mathrm{~A}$ & \\
\hline Screen Dissipation & $665 \mathrm{~W}$ & $1034 \mathrm{~W}$ & $5000 \mathrm{~W}$ \\
\hline Grid Drive Voltage & 380 Volts & 330 Volts & \\
\hline Peak Grid Current & 0 & 0 & \\
\hline Grid Dissipation & 0 & 0 & $2000 \mathrm{~W}$ \\
\hline
\end{tabular}

\section{Table II}

Summary of Tube Operating Parameters

$$
\begin{aligned}
& E_{b b}=12 \mathrm{Kv} \\
& E_{c 2}=1500 \text { volts } \\
& E_{c 1}=-380 \text { volts }
\end{aligned}
$$




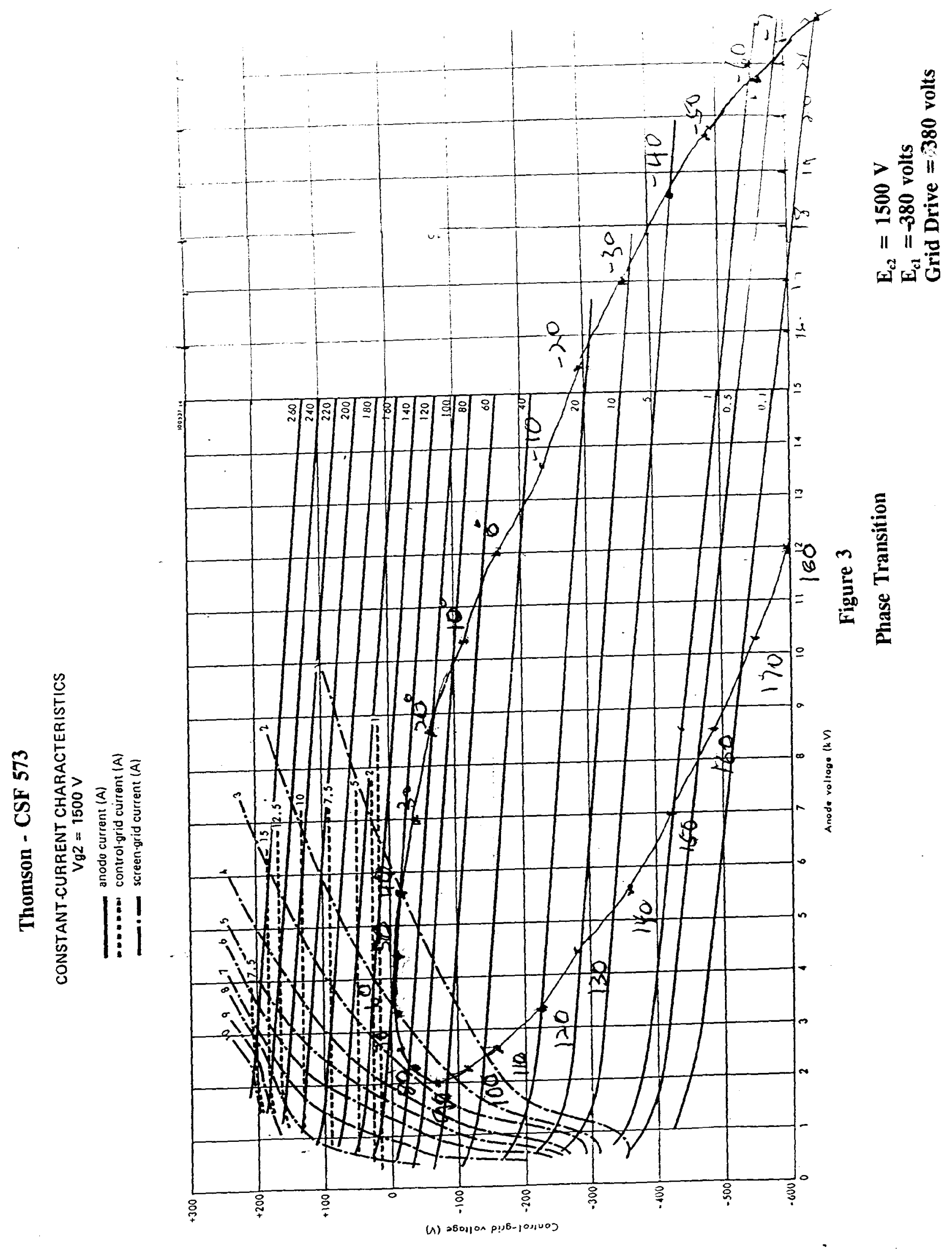




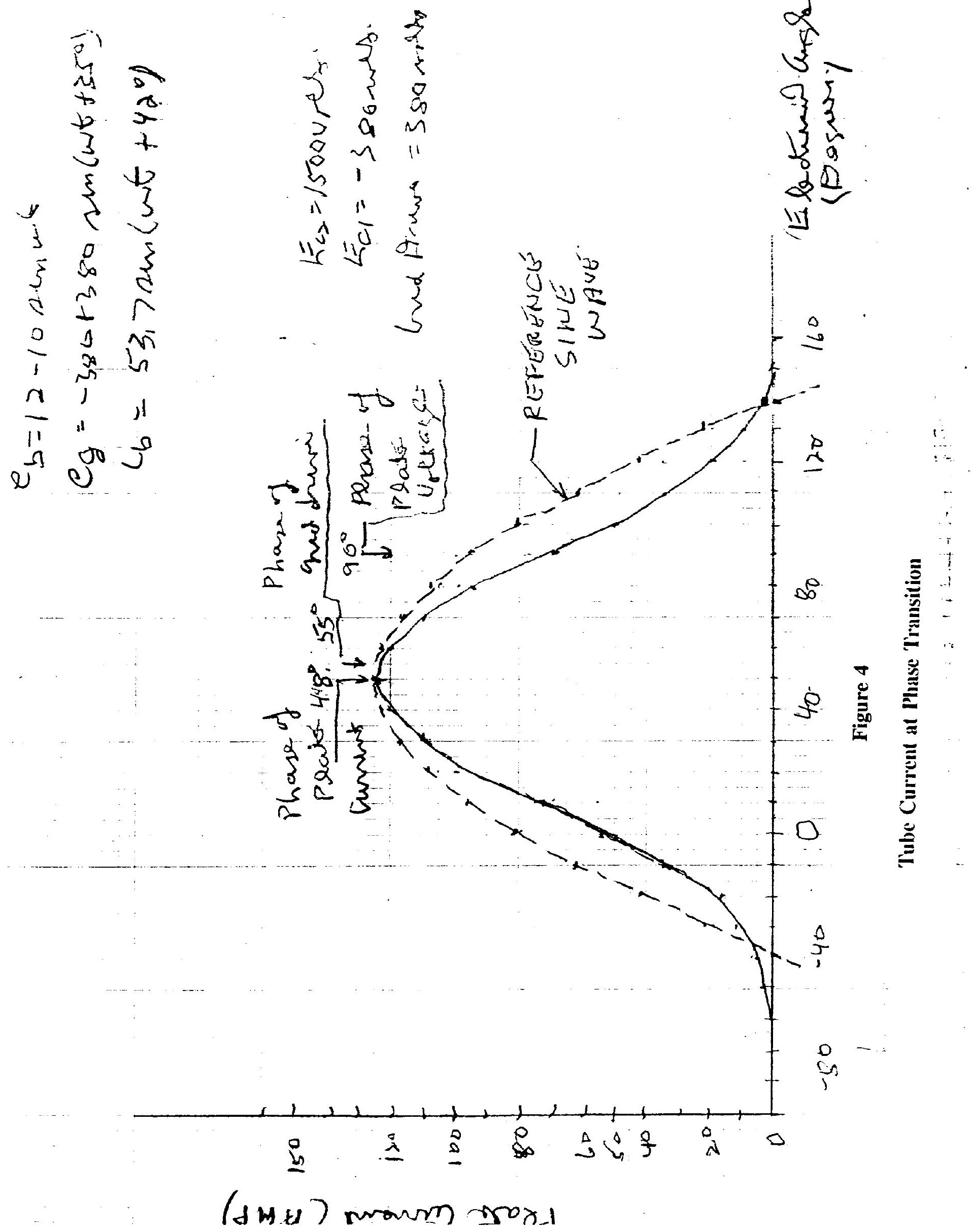

